University of Nebraska - Lincoln

DigitalCommons@University of Nebraska - Lincoln

USDA Wildlife Services - Staff Publications

U.S. Department of Agriculture: Animal and Plant Health Inspection Service

$12-1-2021$

\title{
Towards a more comprehensive understanding of wild pig (Sus scrofa) impacts on agricultural producers: Insights from a Texas case study
}

\author{
Keith M. Carlisle \\ Warner College of Natural Resources, keith.m.carlisle@usda.gov \\ Nicole Didero \\ USDA APHIS National Wildlife Research Center \\ Sophie McKee \\ USDA APHIS National Wildlife Research Center \\ Julie Elser \\ USDA APHIS National Wildlife Research Center \\ Stephanie A. Shwiff

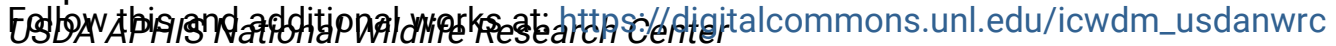 \\ Part of the Natural Resources and Conservation Commons, Natural Resources Management and \\ Policy Commons, Other Environmental Sciences Commons, Other Veterinary Medicine Commons, \\ Population Biology Commons, Terrestrial and Aquatic Ecology Commons, Veterinary Infectious Diseases \\ Commons, Veterinary Microbiology and Immunobiology Commons, Veterinary Preventive Medicine, \\ Epidemiology, and Public Health Commons, and the Zoology Commons
}

Carlisle, Keith M.; Didero, Nicole; McKee, Sophie; Elser, Julie; and Shwiff, Stephanie A., "Towards a more comprehensive understanding of wild pig (Sus scrofa) impacts on agricultural producers: Insights from a Texas case study" (2021). USDA Wildlife Services - Staff Publications. 2466.

https://digitalcommons.unl.edu/icwdm_usdanwrc/2466

This Article is brought to you for free and open access by the U.S. Department of Agriculture: Animal and Plant Health Inspection Service at DigitalCommons@University of Nebraska - Lincoln. It has been accepted for inclusion in USDA Wildlife Services - Staff Publications by an authorized administrator of DigitalCommons@University of Nebraska - Lincoln. 


\title{
Towards a more comprehensive understanding of wild pig (Sus scrofa) impacts on agricultural producers: Insights from a Texas case study
}

\author{
Keith M. Carlisle ${ }^{\text {a,b, }}$, Nicole Didero ${ }^{\text {b,c }}$, Sophie McKee ${ }^{\text {b,c }}$, Julie Elser ${ }^{b}$, Stephanie A. Shwiff ${ }^{b}$ \\ ${ }^{a}$ Department of Human Dimensions of Natural Resources, Warner College of Natural Resources, Colorado State University, 1480 Campus Delivery, Fort Collins, CO, \\ 80523, USA \\ ${ }^{\mathrm{b}}$ National Wildlife Research Center, United States Department of Agriculture, Animal and Plant Health Inspection Service, Wildlife Services, Fort Collins, CO, 80521, \\ USA \\ ${ }^{\mathrm{c}}$ Department of Economics, College of Liberal Arts, Colorado State University, C138 Clark Building, Fort Collins, CO, 80523, USA
}

\section{A R T I C L E I N F O}

\section{Keywords:}

Sus scrofa

Feral swine

Damage estimates

Agriculture

Invasive species management

\begin{abstract}
A B S T R A C T
This research investigates the impacts of invasive wild pigs (Sus scrofa Linneaus) on agricultural producers in Texas, with the aim of identifying and describing all categories of wild pig impacts and quantifying the extent of producers' over- or underestimation of their total wild pig-related costs in 2018, as compared to calculations based upon data subsequently provided by the producers about individual wild pig-related costs and losses. Based on interviews with 23 producers in 16 Texas counties, we identified more than 20 discrete categories of negative impacts and negligible positive impacts associated with wild pigs. Among them were categories that have not been described or included in previously published economic estimates of wild pig impacts on producers, such as (i) additional time and fuel expenses incurred at harvest on account of damaged fields, (ii) reduced yield on replanted crops following wild pig damage, (iii) loss of arable land due to erosion caused by wild pigs, (iv) reduced livestock weight conversion, and (v) increased livestock depredation by coyotes on account of damage to fencing caused by wild pigs (a more speculative impact). We also found that participants underestimated their total costs associated with wild pig impacts by a factor of nearly three, and the extent of underestimation was even greater among crop producers (4.6), largely because of unconsidered opportunity costs. With these findings, we call attention to the need for economic estimates that better capture the full range of costs imposed on agricultural producers by wild pigs.
\end{abstract}

\section{Introduction}

Wild pigs (Sus scrofa Linneaus), also known as feral swine, feral hogs, wild hogs, and wild boar (Keiter et al., 2016), are an invasive species in the United States present in at least 35 states (Corn and Jordan 2017). The species is responsible for wide-ranging negative impacts to human and ecological communities, including (i) damage to crops (Anderson et al., 2016; McKee et al., 2020); (ii) depredation of livestock (Anderson et al., 2019); (iii) vehicle collisions (Beasley et al., 2018); (iv) damage to developed property (e.g., landscaping and fences) (Beasley et al., 2018); (v) transmission of parasites, bacteria, and viruses to humans and animals (Bevins et al., 2014); and (vi) depredation of native flora and fauna and alteration of habitats and degradation of water quality (Barrios-Garcia and Ballari 2012; Bolds et al., 2021). Of the various categories of wild pig impacts, agricultural losses may be among the costliest. As Bevins et al. (2014) noted, however, there are relatively few robust estimates of agricultural losses to wild pigs. This represents a critical deficiency, as robust estimates are needed to inform the allocation of resources towards efforts to control wild pig populations and mitigate their damages (Beasley et al., 2018).

The most widely cited economic estimate of wild pig losses in the United States comes from Pimentel (2007) (e.g., Carlisle et al., 2020; Grady et al., 2019; Caplenor et al., 2017). The author estimated that wild pigs caused at least US $\$ 1.5$ billion in crop losses and control costs annually, a figure that represented a back-of-the-envelope style calculation based upon a rough estimate of 5 million wild pigs in the U.S. and an assumption of US\$300 in crop losses and control costs per wild pig (Pimentel 2007). Little information was provided about the types of

\footnotetext{
* Corresponding author. Department of Human Dimensions of Natural Resources, Warner College of Natural Resources, Colorado State University, 1480 Campus Delivery, Fort Collins, CO, 80523, USA.

E-mail address: keith.carlisle@colostate.edu (K.M. Carlisle).
} 
costs included in the categories of "crop losses" and "control costs." In recent years, more robust estimates of agricultural losses from wild pigs have been produced using self-reported survey data, with studies generally focusing on particular U.S. regions and/or agricultural sectors or resources. For example, Anderson et al. (2016) found that producers of six high value crops in 10 states suffered approximately US $\$ 190$ million in crop losses in 2014 on account of wild pig damage. In addition, McKee et al. (2020) found that producers of six different crop types in 12 states lost an estimated US\$272 million in 2018 on account of wild pig damage to the crops. While the authors of both studies collected data about wild pig management and control costs, additional harvest costs due to wild pig damage, and damage to specified types of property (e.g., fencing, farm equipment), overall estimates were limited to direct crop damage, and the authors acknowledged that total costs were likely much higher (Anderson et al., 2016; McKee et al., 2020).

Other survey studies, while narrower in geographic scope, have reported a broader range of wild pig-related costs to producers. Mengak (2016), in addition to reporting crop and non-crop damages in a small survey study of Georgia landowners, reported that $23.1 \%$ of respondents grew a less profitable crop to avoid wild pig damage, with an average opportunity cost per producer of US\$14,416.91. Poudyal et al. (2017) used self-reported survey data from landowners in Tennessee to estimate statewide total damages to landowners from wild pigs (US\$27.22 million) and total control costs (US\$2.09 million). While crop damage accounted for roughly half of the damages estimate ( $\$ 13.8$ million), other components included opportunity costs from growing a less vulnerable/less profitable crop (US\$2.3 million), loss of livestock feed (US $\$ 2.2$ million), damage to pastures (US\$1.8 million), damage to livestock (US\$1.3 million), replanting costs (US\$1.1 million), field re-disking costs (US\$670,180), damage to equipment (US\$179,247), damage to fences (US\$179,094), and loss of hunting lease income (US\$15,364) (Poudyal et al., 2017).

Studies that use self-reported survey data have been the predominant research method for estimating agricultural losses to wild pigs, due in large part to their efficiency and cost-effectiveness for studying large populations. While such studies run the risk of significant over- or underestimation of losses because of their reliance on self-reported data, studies have shown that producers' self-reported estimates of direct crop damage tend to be fairly accurate when compared to field estimates (Elser et al., 2019; Johnson-Nistler et al., 2005; Conover 2002). Like any research method, however, surveys carry limitations. For example, surveys offer relatively limited means for verifying how a respondent arrived at a particular cost estimate, including whether they considered factors such as time or labor associated with a category of wild pig damage or cost (even when directed to do so by the questionnaire item). Surveys may also be a less suitable method when the research objective is more exploratory in nature - e.g., studies aimed at identifying new categories of wild pig impacts - or when the type of damage under investigation would be challenging for a producer to recollect and/or quantify. As an example of the latter, Boyer et al. (2020) were interested in understanding whether soil disturbance by wild pigs resulted in reduced pecan harvest efficiency, an impact that would be challenging for a producer to estimate with reasonable precision. They employed a field-based "before-after control-impact" study design and found that $34 \%$ of pecans were not harvested on account of wild pig soil disturbance, a figure that could be used to calculate economic losses at harvest.

For studies that are more exploratory in nature, qualitative case studies (Yin 2003), such as those that use interviews and/or focus groups for data collection, can address some of the limitations of other research methods. Though infrequently used in economic research because they can be costly and do not typically yield statistically generalizable findings, case studies allow a researcher to gain an in-depth and highly nuanced understanding of a phenomenon, such as the impacts of wild pigs on agricultural producers. As Floress and Sachdeva (2019) assert, smaller-scale case studies are an important methodology for identifying knowledge gaps generated through other data collection methodologies. Insights gained from case studies can generate new hypotheses and inform the design of better survey questionnaires. In that sense, case studies are a valuable, if underutilized, complement to survey and field-based studies. To our knowledge, there have been no published qualitative case studies that explore the full range and costs of wild pig impacts to agricultural producers. This research, which focuses on crop and livestock producers across the State of Texas, addresses that gap.

\subsection{Research objectives}

Our objectives for this study were to (i) identify and describe all categories of wild pig-related impacts or costs incurred by study participants in 2018; (ii) identify and describe any benefits or income derived by study participants from wild pigs in 2018; and (iii) compare study participants' estimates of their total costs in 2018 from wild pigs to an itemized total we calculated based upon detailed information subsequently provided by participants. With respect to the first objective, we took a broad approach, seeking information about not only crop and livestock losses and control costs, but also difficult-to-quantify costs, such as additional wear-and-tear on equipment. Thus, the focus of our study was on impacts and costs for producers rather than the narrower category of damage to agricultural resources. For the second objective, we investigated whether participants benefited in any direct or indirect ways from wild pigs (e.g., by leasing wild pig hunting rights) to determine whether their losses were offset by any wild pig-related gains. While our primary goal for the first two objectives was to provide qualitative description of cost and benefit categories, we also endeavored to (i) provide quantitative estimates of such categories, but only to the extent the producers provided cost information (i.e., we did not use data from external sources); and (ii) indicate when participants were unable or used rough heuristics to estimate costs or benefits for particular categories. For the third objective, we were interested in understanding the types of impacts, benefits, and costs participants generally considered and reported when asked to give their best estimate of the total losses and costs they experienced because of wild pigs in a particular year. As well, we wanted to know whether participants underestimated or overestimated their total costs when compared to our detailed accounting. These findings all have important implications for future studies that seek to estimate the costs wild pigs impose on agricultural producers.

\section{Methods}

\subsection{Study area}

We selected Texas as the site for this case study on account of its large wild pig population, the importance of agriculture to the Texas economy, and the magnitude and range of damages the species causes to agriculture in the state. Texas is home to the largest wild pig population in the United States, with an estimated 2.5 million wild pigs in 2016 (Lewis et al., 2019). It also has one of the largest agriculture industries in the nation. In terms of agricultural cash receipts, Texas ranked third in the United States in 2014 behind California and Iowa (Gleaton and Robinson 2016). Additionally, Texas ranked first among states in 2014 in the number of farms and ranches and in sales of cattle and calves, sheep and wool, goats and mohair, and cotton (Ibid). Other important crops in the state include corn and other feed grains (e.g., sorghum), oilseeds (e.g., soybeans and peanuts), and pecans (NASS 2017). With wild pigs present in nearly every county of the state (Froehly et al., 2020), studies have found that Texas producers have suffered greater crop and livestock losses in recent years than producers in other states affected by wild pigs (Anderson et al., 2016; McKee et al., 2020). Texas was therefore an appropriate setting to investigate the full range of potential costs and benefits associated with wild pigs for agricultural producers. 


\subsection{Sampling strategy}

In drawing our sample of producers, we used a purposive sampling strategy - i.e., a nonrandom technique whereby participants are deliberately selected based upon their knowledge or experience (Tongco 2007). This strategy is commonly used in qualitative research where the goal is not statistical generalization, but rather the efficient generation of rich data from individuals with direct knowledge and expertise about the phenomenon under study (Etikan et al., 2016). Our criteria for sample members were that (i) they were crop and/or livestock producers in Texas, and (ii) they had personally experienced wild pig damage on their operation. To ensure maximum variation, our criteria for the sample were that its members, as a whole, produce a diversity of crop and livestock resources and represent a broad cross-section of geographical regions in the state. Regarding the latter, Texas comprises over $260,000 \mathrm{mi}^{2}$ of land and multiple geographical regions with different landscape attributes, including differing soil types, land cover, and climates. These attributes control a region's suitability for different types of agricultural production, and thus, achieving geographical diversity in our sample helped ensure agricultural resource diversity.

To identify sample members, we relied on personnel from the Texas office of USDA APHIS Wildlife Services (WS), a federal program charged with resolving human-wildlife conflict. In Texas and other states affected by wild pigs, WS personnel assist with the control of wild pigs on public and private lands, typically through a cost-sharing arrangement with landowners and/or local associations. WS personnel in the Texas program identified 23 livestock and crop producers in 16 counties across the state who were receiving wild pig control services from WS and who were willing to be interviewed for this study (Fig. 1). Although financial constraints prevented us from interviewing more producers, the 23 sample members represented a broad cross section of resource production and geographical regions. The 16 counties represented in our sample were: Uvalde, Edwards, Sutton, Kimble, Colorado, Jim Wells, Cameron, Nolan, Briscoe, Hall, Delta, Collin, Hunt, Rockwall, Brown, and Comanche. Given that all producers in our sample were motivated to seek assistance from WS in controlling wild pigs on their operations, they are not necessarily representative of Texas agricultural producers more generally in terms of the wild pig damages they experienced - i.e., they may have experienced greater than typical wild pig damages. However, as statistical generalization was not an objective of this study, this was not problematic; rather, it helped ensure that the individuals we interviewed were in a position to give us an understanding of a broad range of wild pig-related damages, losses, costs, and benefits that a Texas agricultural producer could potentially experience.

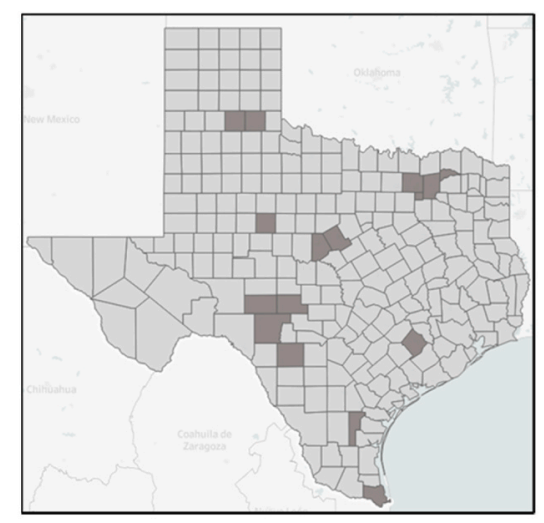

Note: Counties shaded in dark grey indicate locations of participants' operations

Fig. 1. Texas Counties Represented in Sample

Note: Counties shaded in dark grey indicate locations of participants' operations.

\subsection{Data collection}

We conducted in-person, semi-structured interviews with the 23 producers between August 6, 2019 and November 20, 2019. Interviews were typically performed on a producer's operation, and in some cases, we toured the operation to observe signs of wild pig damage and wild pig control tools. In each interview, after collecting information about the size and nature of the producer's operations, we asked the producer to provide their best estimate of the total amount of money that wild pigs cost them in 2018, including direct and indirect resource losses, control costs, and the value of any extra time spent on resource production on account of wild pigs. We then asked a series of questions to elicit information (including costs) concerning (i) all wild pig control or damage management techniques that the producer and/or WS personnel used on their operation in 2018; (ii) all wild pig-related losses or costs associated with the production of any crops on the producer's operation; (iii) all wild pig-related losses or costs associated with the production of any livestock on the producer's operation; (iv) all wild pig-related losses or costs associated with damage to any property on the producer's operation, including planting and harvesting machinery, irrigation systems, vehicles, storage facilities, residences, and infrastructure to support livestock production; ( $v$ ) any other miscellaneous negative impacts of wild pigs on the producer and/or their operation, including inability to produce a preferred resource on account of vulnerability to wild pig damage (i.e., opportunity costs), negative impacts to wildlife and game hunting on the producer's property, and negative impacts on the producer's quality of life; and (vi) any benefits enjoyed by the producer on account of wild pigs. During data collection, we incorporated iterative processes such that when we learned of a new category of loss or cost during an interview, we amended our interview guide to incorporate a question concerning the new category. In that sense, our interview guide was not static, but rather flexible and evolving as we gained additional insight.

\subsection{Data analysis}

All interviews were digitally recorded, and verbatim transcripts were produced for analysis. To identify and describe categories of wild pigrelated costs and benefits (research objectives one and two), all transcripts were uploaded into QSR NVivo qualitative analysis software for analysis and thematic coding. An inductive coding process was used whereby a code was created in NVivo whenever a new category of wild pig costs or benefits emerged from the reading of transcripts. Once all transcripts were analyzed and coded in NVivo, quantitative counts and comparisons of the various costs and benefits (i.e., coded themes) were performed in NVivo and recorded on a Microsoft Excel spreadsheet.

To determine how a producer's estimate of costs (inclusive of losses, damages, etc.) given at the beginning of an interview (referred to as the "stated value") compared to our own calculation based on the producer's subsequent itemized loss and expense responses (referred to as the "calculated value"), we systematically analyzed all transcripts and created an itemized accounting of all costs revealed during the interviews on a Microsoft Excel spreadsheet. If a producer could not provide an estimate for an identified cost or benefit, the item was not included in the producer's calculated value. For costs associated with equipment with a multi-year useful life (e.g., fencing and hunting gear), we allocated a portion of the costs to 2018 based on the producer's estimate of the total cost divided by the producer's estimate of the equipment's useful life. Once we determined a producer's calculated value for 2018, we calculated a "multiplication factor" for the producer equal to the ratio between the calculated value and the stated value. For example, if a producer's stated value in 2018 was US $\$ 50,000$, but the calculated value was US $\$ 100,000$, the multiplication factor would be 2.0. We also calculated the average multiplication factor score for producers in each of three categories: crop producers, livestock producers, and crops/livestock "mixed" producers. As well, we analyzed the 
transcripts for information concerning the types of costs and losses producers generally considered and omitted when providing their total estimate at the beginning of interviews. Doing so allowed us to draw conclusions about the types of wild pig-related costs that may be overlooked or omitted by producers when asked to report their total wild pigrelated costs.

\section{Results}

\subsection{Participant characteristics}

Of the 23 participants, six were crop producers, six were livestock producers, and 11 produced both crop and livestock resources. Across all participants, the following nine crops were produced in 2018 (with total acreage): (i) cotton (16,106 acres), (ii) corn (11,875 acres), (iii) hay (4500 acres), (iv) soybeans (3900 acres), (v) wheat (3620 acres), (vi) sorghum (3066 acres), (vii) peanuts (1720 acres), (viii) oats (460 acres), and (ix) pecans (70 acres). Additionally, the following livestock types were produced among participants in 2018 (with total number of head): cattle (11,690), goats (6947), and sheep (3850). The size of participants' operations ranged from 300 acres to 8500 acres, with an average of 3550 acres and a median of 3500 acres.

\subsection{Management and control costs}

All participants received wild pig control assistance from WS in 2018 under a cost-sharing arrangement. ${ }^{1}$ As such, their control and management costs may have been less than those of similarly situated producers who did not receive such assistance. WS employees used any combination of ground shooting, trapping, deploying snares, and aerial gunning, as appropriate, to control wild pigs on participants' operations. Two participants relied solely on assistance from WS and did not incur any additional costs in 2018 associated with management or control of wild pigs. The remaining 21 participants employed additional measures and incurred additional costs to control wild pigs or manage damage.

\subsubsection{Fencing}

Fencing was the most common wild pig management measure employed by participants. Fifteen participants installed, maintained, and/or upgraded fencing to mitigate damage from wild pigs. ${ }^{2}$ This included permanent fencing, usually made from high tensile net wire, and temporary electric fencing, often installed at planting and removed after harvest. Although protection from wild pigs was a primary motivation for using fencing for all participants, for some it also protected against other nuisance wildlife (e.g., coyotes and deer) and/or prevented livestock from escaping. As this suggests, determining the portion of fencing costs to allocate to wild pig management can be a challenge. Total costs for purchasing and installing permanent net wire fencing, including materials and labor, ranged from approximately US $\$ 10,000$ to US $\$ 22,500$ per mile, depending on factors such as the number of gates, the terrain, and the inclusion of barbed wire. Purchase and installation costs were typically incurred over a period of years as participants incrementally added or upgraded sections of fencing. The maximum cost any participant incurred in 2018 was US $\$ 26,175$.

Seven participants used temporary electric fencing in addition to, or in lieu of, permanent fencing. The cost of electric fencing was significantly lower than permanent net wire fencing and ranged from US\$500

\footnotetext{
1 Cost sharing arrangements varied widely across the state. In some cases, counties or producer associations subsidized the assistance from WS, and the cost to the producer ranged from no cost to a modest annual fee paid to the producer association. In no case, however, did the cost to a producer amount to more than half the actual cost of the services provided by WS.

${ }^{2}$ Several participants leased their land and lacked incentive to incur the substantial costs associated with installing fencing.
}

for a small section of fencing (less than a mile) to US\$50,000 for 20 miles of electric fencing. However, electric fencing was reportedly less successful in deterring wild pigs than strong net wire fencing, and it was associated with high maintenance costs. For example, one participant who used electric fencing to deter wild pigs from damaging crops reported that during the 182 days in 2018 that his electric fence was installed, one employee spent on average one hour each day checking the entire length for breaches and mending any damage. His employee was paid US $\$ 20 /$ hour, bringing his total estimated maintenance cost in 2018 to US $\$ 3,640$, not including the time required to install and remove the fence. Even with a high-quality net wire fence, however, yearly maintenance costs were high because wild pigs were capable of damaging fences and exploiting washouts under fences caused by rain. One participant told us that his employee checked the entire perimeter fence surrounding his 6000-acre operation once a month to look for wild pig damage and to make repairs. He said the employee spent two to three full days each month on the task, amounting to roughly one month's time in 2018. Another producer told us that he spent a half-hour each day on average monitoring his fence for wild pig damage and making repairs.

\subsubsection{Traps}

Nine participants built or purchased traps for wild pigs, and all but one of them used multiple traps (up to 10). Most of the traps were box traps or corral-type traps, ranging in price from US\$175 to US\$2,000, depending on size, materials, and whether the trap was made by the participant or purchased from a supplier. In addition, one participant purchased a high-tech trap with a camera that could be operated remotely through a cell phone for US $\$ 3,500$, with an annual cellular service plan of US $\$ 300$. Participants also told us that to increase trap effectiveness, they relocated traps multiple times per year, which entailed additional time and cost, along with the time associated with repairing traps and removing and disposing of animals. As one participant explained, "If I have a trap set ... and I've got hogs in it, the first thing I've got to do is shoot them. Then I've got to bury them, so I've got to get my Ford backhoe, and then I've got to move that trap and then I've got to rebait it. So you're talking about a half a day." While most participants found it challenging to estimate total time spent on trap operation in 2018, one participant who used seven traps on his 6000 acre operation estimated that he or an employee spent about two hours a day for 90 days in 2018 servicing and maintaining traps, totaling roughly 180 hours of labor.

\subsubsection{Aerial gunning}

In areas where aerial gunning of wild pigs was appropriate (i.e., nonresidential areas lacking dense ground cover), there was a consensus among participants that aerial gunning was the most effective method for eliminating large numbers of wild pigs. While 14 participants were provided aerial gunning assistance by WS in 2018, three participants hired private helicopter services in 2018 for wild pig control. The price for a private helicopter varied widely, ranging from US\$375/hour to US $\$ 1200 /$ hour. Total per-participant helicopter costs for the three participants were US $\$ 3000$, US $\$ 3600$, and US $\$ 11,250$.

\subsubsection{Ground shooting}

Eight participants reported that they and/or family members hunted wild pigs on their operation in 2018 to control the population. As wild pigs were primarily active at night, several participants purchased night vision gear as well as semi-automatic rifles to hunt wild pigs. Among the five participants who reported buying hunting gear exclusively for the purpose of controlling wild pigs on their property, expenditures ranged from US $\$ 750$ for one participant who only purchased a semi-automatic rifle to US\$40,000 for a participant who purchased two rifles, a pair of suppressors, a pair of thermal vision scopes, a pair of night vision goggles, and ammunition for himself and a family member (the average expenditure was US\$18,130). Not all gear-related costs were incurred in 
2018, but we allocated a portion of the costs to 2018 based upon the expected useful life of the gear, which varied depending upon the gear type. Among the eight participants who used ground shooting, their time spent on the activity ranged from roughly six nights in 2018 for one participant to three nights per week, every week for another. Additionally, two participants reported that they guarded their fields every night during the three-week planting season, and one also spent US $\$ 3500$ in 2018 to hire additional help with guarding his fields during that time. For the two participants who stayed up every night during planting season, the lack of sleep also took a toll on their productivity, though they were unable to quantify the impacts.

\subsubsection{Snares}

Snares were a relatively low-cost wild pig control method used by three participants (all livestock producers) in 2018. The reported cost of a single snare was, on average, US\$3.20, and total per-participant expenditures on snares in 2018 were US $\$ 60$, US $\$ 360$, and US $\$ 600$. However, as one participant explained, "snares aren't that expensive, but ... you've got the fuel, and the wear and tear on the vehicle. It was 45 miles you had to go over every day [to check on snares]." While likely significant, no participant could provide an estimate of total additional time or fuel expenses associated with the use of snares in 2018.

\subsection{Crop damage/loss}

Among the nine crop types produced by study participants in 2018, the average cost of wild pig damage per acre planted was greatest for pecans (Table 1 ). Only one participant produced pecans, and he experienced US\$22,000 in pecan damages on 70 acres of pecan trees, amounting to US\$314.29 in damages per acre. The average total cost of wild pig crop damage was greatest for peanut and corn crops. Three participants produced peanuts, and they were unable to estimate damage by acreage because damage was sometimes not visible (vines were often left intact) and/or the peanuts on a vine were only partially consumed. Damage or loss was calculated based upon the expected yield of an acre or by comparison to clearly undamaged acres on the producer's operation. Their estimated peanut damage costs in 2018 were US $\$ 10,000$ (600 acres planted), US\$52,000 (400 acres planted), and US $\$ 185,000$ (720 acres planted). With regard to corn, the average cost of damage per producer (out of six) was US $\$ 32,208$, with a high of US $\$ 56,210$ (4000 acres planted) and a low of US $\$ 4000$ (1000 acres planted). The average percentage of damaged acres was $5.69 \%$, with a high

Table 1

Direct crop damage in 2018.

\begin{tabular}{llllll}
\hline Crop & $\begin{array}{l}\text { Number of } \\
\text { producers }\end{array}$ & $\begin{array}{l}\text { Total } \\
\text { acreage }\end{array}$ & $\begin{array}{l}\text { Average \% } \\
\text { acres } \\
\text { damaged }\end{array}$ & $\begin{array}{l}\text { Average \$ } \\
\text { damage per } \\
\text { producer }\end{array}$ & $\begin{array}{l}\text { Average } \$ \\
\text { damage per } \\
\text { acre } \\
\text { planted }\end{array}$ \\
\hline Cotton & 7 & 16,106 & $<1.0$ & 4428.57 & 1.92 \\
Corn & 6 & 11,875 & 5.69 & $32,208.34$ & 28.82 \\
Hay & 8 & 4500 & 13.36 & 7262.50 & 15.93 \\
Soybeans & 3 & 3900 & .67 & 233.33 & 0.18 \\
Wheat & 5 & 3620 & 6.0 & 646.67 & 1.24 \\
Sorghum & 4 & 3066 & 8.5 & $13,666.67$ & 27.23 \\
Peanuts & 3 & 1720 & NA & $82,333.34$ & 134.55 \\
Oats & 5 & 460 & 23.75 & 3575.00 & 45.55 \\
Pecans & 1 & 70 & NA & $22,000.00$ & 314.29 \\
\hline
\end{tabular}

of $20 \%$ and a low of $0.5 \%$. While no crop types were entirely unaffected by wild pigs, only one of three soybean producers in our sample experienced wild pig damage to soybeans, with damage occurring on $2 \%$ of the producer's 1300 soybean acres, for a loss of US $\$ 700$. Similarly, only one of seven cotton producers in our sample experienced nonnegligible damage to cotton, with damage occurring on $5 \%$ of the producer's 7700 cotton acres, for a loss of US $\$ 31,000 .^{3}$

A more difficult-to-estimate crop loss may occur when a crop is replanted following wild pig damage. Crops like corn and peanuts are especially vulnerable to damage shortly after planting, as wild pigs will root up and consume the seeds or young shoots. Several participants explained that if a producer replants the damaged acres, crops that emerge later in the growing season typically have a lower yield. Two participants replanted corn and one replanted peanuts in 2018 following wild pig damage. One estimated that the 40 acres of corn he replanted produced about half the expected yield, while the other two provided no estimates.

\subsection{Planting and harvest costs}

A majority of participants reported varying degrees of damage to fields from wild pig rooting behaviors in 2018. The resulting unevenness of the ground contributed to additional labor and fuel costs for 13 participants at planting, as they had to level or re-disk their fields prior to planting ${ }^{4}$ or significantly slow their tractor speed to navigate rough terrain. Most affected participants estimated they spent between roughly $30 \%$ and $50 \%$ more time and fuel at planting. At the low end, this amounted to two additional hours of labor and fuel, totaling approximately US $\$ 80$. At the high end, a participant reported multiple additional days' labor and fuel to level and prepare fields at a cost of US $\$ 4500$.

Wild pig damage resulted in similar expenses at harvest, with most of the 12 affected participants reporting that they had to slow down their harvest machinery by $30 \%-50 \%$, adding between several hours and two additional days to navigate rough terrain and to harvest crops that had been trampled to the ground. In the case of pecans, the additional time required was greater. The single pecan producer in our sample reported that wild pigs engaged in significant rooting around the base of his pecan trees in 2018, resulting in an accumulation of dirt and mud on pecans that had fallen to the ground. While a hopper of pecans would ordinarily have taken him between $45 \mathrm{~min}$ and an hour to mechanically clean, a hopper full of the soiled pecans required between six and eight hours to clean as they were run through the mechanical cleaner multiple times. Many were lost in the process, as their shells were cracked from repeated cleanings.

Participants who experienced rougher terrain at planting and/or harvest also spoke of additional wear and tear to their machinery. Most were unable to estimate how much the additional wear and tear might have cost them in the way of more frequent servicing and new parts. However, one producer explained that when harvesting soybeans, he runs the combine harvester's flex header on the ground. He said he has broken sickle sections and sickle guards from unexpectedly hitting dirt

\footnotetext{
${ }^{3}$ Multiple participants reported hearing that cotton seed contains chemicals toxic to wild pigs, an attribute they believed explained the relative lack of damage to cotton. The participant who experienced nonnegligible damage to cotton explained that the damage occurred because wild pigs were rooting for unharvested peanuts planted on the same field the previous year.

${ }^{4}$ Several participants explained that planting on an uneven field, in addition to adding additional tractor time and fuel costs, can result in reduced crop yield because crops that emerge in lower spots often produce a lower yield. This may be an additional cost of wild pigs to producers who do not level their fields prior to planting. In addition, one participant who produced corn on raised beds noted that wild pigs had damaged the beds, leading to areas in the field that did not drain properly. This also resulted in reduced yield for the plants that emerged in saturated soil.
} 
mounds created by wild pigs. He placed the servicing and repair costs attributable to wild pigs in 2018 at US\$5000. Another participant damaged his combine harvester when he ran over a wild pig with piglets in 2018, though the damage was relatively minor, costing US\$75 to repair. Wear and tear on the body may also result from running machinery on damaged fields. In this regard, a participant believed that the constant bouncing he experienced on his tractor while driving over wild pig damage caused or contributed to a back problem that required recent surgery and a loss of productive time (no portion of the costs were attributed to wild pigs in our analysis).

\subsection{Damage to pastures}

Six livestock producers in our sample reported wild pig rooting damage to pastures in 2018. Half did not incur costs associated with the damage other than a loss of grazing area. The other three noted that weeds emerged in areas disturbed by wild pigs, requiring them to do additional spraying of their pastures to manage the weeds. Of those three, one built a custom boomless sprayer because the wallows created by the wild pigs were too deep for a standard sprayer to maneuver. The cost of the sprayer, based on labor and materials, was US $\$ 1800$. Total costs incurred to spray damaged pastures ranged from US $\$ 1500$ to 25,000 . The participant with the highest cost explained that he would have sprayed his pastures (totaling 1800 acres) even if there were no wild pig damage, but that he likely doubled the amount he would have sprayed on account of the wild pig damage. His total expenditures on spraying pastures in 2018 were US $\$ 50,400$.

\subsection{Livestock loss}

\subsubsection{Goats and sheep}

Among the five participants who produced goats and/or sheep, ${ }^{5}$ all experienced depredation in 2018 - primarily of kids or lambs - that they attributed to wild pigs. None directly witnessed a depredation event in 2018, but several reported that livestock losses declined after the removal of wild pigs on their operation. In addition, most acknowledged that it was often difficult to distinguish coyote depredation from wild pig depredation. Wild pigs reportedly leave little or nothing behind in the way of remains, making it challenging to determine whether livestock was initially killed by a coyote and later scavenged by a wild pig, or whether a wild pig was responsible for the killing. As one participant explained, "You don't find [the kids and lambs taken by wild pigs] ... And with a newborn, they eat everything. You don't find anything. You just see a ewe with afterbirth on them ... one day [a nannie will] have twins and next day she'll have one and next day she doesn't have any." Two participants were confident that wild pigs also played a role in coyote depredation because wild pigs created holes or gaps in their fences, thereby making it easier for coyotes to reach their livestock. Another participant explained the difficulty in knowing how many sheep were lost: "I'm not sure how many [were lost]. Unless you get your sheep up every day and count them, you don't really know. You just know what you sold last year and what you sold this year, and so forth."

Because of this uncertainty, sheep and goat producers estimated their losses of lambs and kids based upon an expected yield using historical averages (e.g., 250 Spanish goat nannies should have produced a minimum of 250 kids, equating to a $100 \%$ yield) and their best estimate of what percentage of the losses could be attributed to wild pigs (ranging

\footnotetext{
5 Two participants produced only goats, one produced only sheep, and two produced goats and sheep.
}

from $50 \%$ to $100 \%$ ). Among the four participants who produced goats, one lost $100 \%$ of his expected crop of 225 Spanish goat kids (approximately US $\$ 50,000$ ) and $61 \%$ of his expected crop of 1000 angora goats (approximately US\$65,000). ${ }^{6}$ He attributed $75 \%$ of all goat losses to wild pigs for a total estimated loss of US $\$ 86,250$. The approximate value of goat losses attributable to wild pigs for the other three were US $\$ 16,500$, US $\$ 13,950$, and US $\$ 4375$. Among the three participants who produced sheep, one lost $73 \%$ of his expected crop of 300 lambs (approximately US\$30,660), all of which he attributed to wild pigs. The approximate value of sheep losses for the other two were US $\$ 17,500$ and US $\$ 6875$. One sheep producer also noted that wild pigs regularly ran his sheep off their bed at night, sometimes causing them to run into fencing. He believed the stress may have been responsible for less-than-expected weight gain among his sheep, though he was unable to estimate the cost.

\subsubsection{Cattle}

Among the four participants who produced cattle, only one believed he lost cattle in 2018 to wild pig depredation - a heifer and a bull calf lost during calving that were valued at about US\$5000. He did not witness the depredation, but he said the evidence led him to conclude that wild pigs, rather than coyotes, were responsible. A second cattle producer who operated a dairy farm said that he lost four calves valued at US $\$ 1000$ apiece because they sustained mortal injuries from running into a fence after being spooked. He did not witness the event, but he believed wild pigs were more likely than coyotes to have been responsible. He also explained that cows must reach a certain weight before they are efficient at milk production, and that stressed cows do not gain weight as quickly. They therefore require more time and inputs before becoming productive. He believed that wild pigs were responsible for stress and a resulting lack of weight gain for a group of 200 cows in 2018 , and he estimated the cost to him as roughly US $\$ 2000$ in increased inputs. Two other participants also reported that wild pigs were likely responsible for their cattle not gaining the expected amount of weight in 2018. One, who said that wild pigs destroyed his pastures, estimated $15-20 \%$ less weight gain for a group of 98 calves, costing him roughly US $\$ 16,500$ on the sale of the calves. The second said that wild pigs regularly got into his cattle feeding troughs in 2018, chasing off his cattle and defecating in the feed. As a result, his cattle would often not consume the feed. He kept weight-gain records for 200 head of cattle over a 90-day period in 2018. Instead of gaining an expected two pounds per day, they gained about one pound per day, resulting in an estimated US $\$ 27,000$ loss in weight conversion.

\subsection{Livestock disease}

Although wild pigs can transmit disease to livestock (e.g., pseudorabies and brucellosis) (Bevins et al., 2014), participants were unable to attribute any livestock infections to wild pigs. However, one participant, who was in the process of vaccinating livestock against anthrax when we visited his operation, noted that anthrax was never an issue in his region until wild pigs arrived. He speculated that wild pigs may have been responsible for spreading anthrax or releasing the spores when they disturbed the soil. A second participant reported that she vaccinated 94 head of cattle against brucellosis in 2018 at a cost of US $\$ 1316.50$ because she was concerned that her cattle could contract brucellosis from wild pigs. No other participants reported vaccinating cattle against brucellosis in 2018.

\footnotetext{
${ }^{6}$ Angora goats are raised for their hair rather than meat and are a specialty breed that is more difficult to replace. The value provided by the participant is likely very conservative, as he must produce and raise his own replacements. If he is unable to replace an angora goat, he loses expected revenues from the sale of the goat's hair over the goat's expected productive life (up to seven years).
} 


\subsection{Livestock feed and supplements}

All but two livestock producers in our sample reported that wild pigs consumed a portion of their livestock feed or supplements (e.g, protein blocks) in 2018. Most could not estimate how much was lost to wild pigs. However, one reported that he lost US $\$ 5000$ in baled hay to wild pigs in 2018. Another reported that wild pigs consumed about $10 \%$ of the cattle feed in his metal feeders (a loss of about US\$1500) and 10\% of his baled hay (a loss of about US\$2250). A third reported that he lost 40 tons of silage feed worth US $\$ 2800$ after wild pigs destroyed the protective plastic wrap around it. He said wild pigs also consumed about $10 \%$ of the feed in his cattle feeders, for a loss of about US $\$ 3000$.

\subsection{Damage to property/equipment}

In addition to the wear and tear on planting and harvest machinery described earlier, participants reported several other categories of damage to property and equipment caused by wild pigs. Three participants experienced wild pig damage to their livestock watering troughs in 2018 , with the cost of repairs ranging from US $\$ 240$ to US $\$ 1200$. Among crop producers, two participants reported wild pig damage to their irrigation systems in 2018 , costing US $\$ 400$ and US $\$ 1000$ to repair. Several producers also pointed out that when they need to purchase replacement parts for equipment, they may have to drive an hour or more to find a supplier because of their rural location. For example, one participant who damaged his hay cutter driving over wild pig damage to a field said he spent three-quarters of a day driving to Dallas and back to purchase a US $\$ 2300$ spindle for his hay cutter.

\subsection{Miscellaneous costs/impacts}

\subsubsection{Roads}

Other miscellaneous costs in 2018 associated with wild pigs included damage to dirt access roads on participants' operations. Four participants reported that wild pigs dug deep holes in their roads in 2018, but only two paid for repairs, costing US\$700 and US\$2100 in time and materials.

\subsubsection{Erosion}

One participant reported that wild pigs caused erosion along his creek beds from digging up grass. As a result, the creek became about 30 feet wider, and he lost an estimated 15 acres of arable land that he would have used to produce sorghum. He estimated the cost of lost profits from sorghum in 2018 to be US\$2250.

\subsubsection{Lease income/wildlife}

One participant leased out some of his land to other crop producers, and in 2018, those producers renegotiated a US\$7000 rent reduction on account of wild pig damages they suffered the previous year, resulting in a loss of income to the participant. Several other participants leased out hunting rights on their land, and all were concerned that they could lose this income stream (vital to some) because wild pigs were reducing the number of deer and ground-nesting birds on their land. In fact, one participant lost a US\$5000 deer-hunting lease on his land in 2018 because of wild pigs, but he was able to replace it with a duck-hunting lease that generated the same income. The decrease in deer and ground-nesting bird populations also resulted in a loss of recreation opportunity for two participants, who said they can no longer hunt deer or quail on their land because of wild pigs.

\subsubsection{Vehicle collisions}

Though not associated with their land or agriculture operations, four participants reported that they had vehicle collisions with wild pigs in 2018. In fact, one had two collisions with wild pigs that year, and another reported that among his immediate family members, there were three collisions with wild pigs in 2018. Costs associated with the collisions ranged from US $\$ 3000$ to US $\$ 6000$ per collision.

\subsection{Opportunity costs}

More than half of participants (14) reported that the presence of wild pigs on their operation prevented them growing a preferred crop or otherwise using their land for more profitable purposes in 2018. The most common lost opportunity was corn production. Six participants reported that they would have grown corn (or increased corn acreage) in place of a less profitable crop, such as wheat. Opportunity costs from not growing corn (projected profit for corn minus profit from the substituted crop) ranged from US $\$ 40,871$ to US $\$ 140,000$, with an average of US $\$ 88,821$ (two of the six producers provided no estimates of their lost opportunity cost). Another producer reported that he would have replaced 90 acres of cotton with peanuts. He explained that rotating in peanuts before cotton would also lower input costs to grow cotton the following year by roughly US $\$ 100$ per acre on account of organic matter left in the soil. His estimated opportunity cost, including lowered input costs for cotton in 2019 , was US $\$ 104,000$. A second crop producer on a large operation (8500 acres) said he would have increased his peanut acreage and added sorghum acreage, both of which would have lowered his input costs for cotton in 2019. His estimated total opportunity cost, including lowered input costs for cotton in 2019 , was US $\$ 675,000$.

Opportunity costs among livestock producers were generally lower than those for crop producers. One stated that he would have utilized 500 acres to raise goats (opportunity cost of US $\$ 10,000$ ), while another told us that he would have replaced 175 ewes with 350 lambs (opportunity cost of US\$8750). Additionally, three livestock producers said they would have grown feed grains in 2018 , with estimated opportunity costs of US $\$ 9600,15,200$, and 75,000. Finally, one livestock producer speculated that he no longer has turkeys on his land because of wild pigs, and that he would have been able to charge hunters an additional dollar per acre on their hunting leases if he had turkeys. Assuming he would have had turkeys on his land in 2018 were it not for the presence of wild pigs, his estimated opportunity cost was US $\$ 5440$.

\subsection{Summary of producer costs}

A summary of the more than 20 categories of wild pig-related costs and impacts experienced by the Texas producers in 2018 in our study are listed in Table 2. Previously described costs that were not associated with resource production are not included in the table. They included multiple vehicle collisions and loss of lease income from land leased to other crop producers and hunting rights leased to deer hunters.

\subsection{Benefits}

Nearly all participants reported that they experienced no benefits in 2018 associated with wild pigs. No participant, for example, received income from leasing out wild pig hunting rights. Many felt the potential liability and damage to their property outweighed any benefit they may have received in the way of wild pig control. One participant who leased out wild pig hunting rights in previous years explained, "[wild pig hunters] do as much damage as the hogs. I'll have an irrigated crop and they'll just drive across it and leave ruts." Additionally, only one participant sold wild pigs that were trapped on his property in 2018 . He received about US $\$ 2500$ from a certified buying station, but he said that the time and effort required to load and transport live wild pigs to the buyer on multiple trips meant that there was likely no profit for him. The only other participant who reported any benefit from wild pigs was a crop producer who reported that he ate several wild pigs in 2018 that he harvested on his operation (he was unable to estimate the value of the wild pigs he consumed). We note, however, that several producers reported that wild pigs reduced the number of deer on their operation. While this may be a negative impact for those with deer hunting leases on their land, for others it may be a benefit, as deer also damage crops. 
Table 2

Producer costs associated with crop and livestock production (2018).

\begin{tabular}{|c|c|c|}
\hline Cost/Impact & $\begin{array}{l}\text { Crop Production } \\
\text { Related }\end{array}$ & $\begin{array}{l}\text { Livestock } \\
\text { Production } \\
\text { Related }\end{array}$ \\
\hline $\begin{array}{l}\text { Costs to purchase, build, upgrade, and/or } \\
\text { install wild pig management and control } \\
\text { tools or services }\end{array}$ & $\mathrm{X}$ & $\mathrm{X}$ \\
\hline $\begin{array}{l}\text { Time and expense associated with } \\
\text { maintenance, repair, and operation of } \\
\text { wild pig management and control } \\
\text { methods }\end{array}$ & $\mathrm{X}$ & $\mathrm{x}$ \\
\hline $\begin{array}{l}\text { Additional costs at planting (time, fuel) to } \\
\text { level fields or to navigate wild pig } \\
\text { damage }\end{array}$ & $\mathrm{X}$ & \\
\hline Direct crop damage/loss & $\mathrm{X}$ & \\
\hline $\begin{array}{l}\text { Costs associated with replanting and } \\
\text { reduced yield on replanted crops }\end{array}$ & $\mathrm{X}$ & \\
\hline $\begin{array}{l}\text { Reduced yield on crops that emerged in } \\
\text { water-saturated soil caused by wild pig } \\
\text { damage to irrigation systems }\end{array}$ & $\mathrm{X}$ & \\
\hline $\begin{array}{l}\text { Additional costs at harvest because } \\
\text { damaged fields/trampled crops required } \\
\text { slower operation of harvest machinery }\end{array}$ & $\mathrm{X}$ & \\
\hline $\begin{array}{l}\text { Additional time associated with cleaning } \\
\text { accumulated dirt off pecans }\end{array}$ & $\mathrm{X}$ & \\
\hline $\begin{array}{l}\text { Opportunity costs (inability to grow a } \\
\text { preferred crop or otherwise use land for } \\
\text { more profitable purposes) }\end{array}$ & $\mathrm{X}$ & $\mathrm{X}$ \\
\hline $\begin{array}{l}\text { Additional wear and tear on machinery } \\
\text { from operating on damaged fields or } \\
\text { from performing other tasks associated } \\
\text { with wild pigs (e.g., regularly driving the } \\
\text { length of a perimeter fence to check for } \\
\text { fence damage or to check on snares) }\end{array}$ & $\mathrm{X}$ & $\mathrm{X}$ \\
\hline $\begin{array}{l}\text { Bodily injury possibly attributable to } \\
\text { repeated operation of machinery over } \\
\text { damaged fields }\end{array}$ & $\mathrm{X}$ & \\
\hline $\begin{array}{l}\text { Direct damage to property and time/ } \\
\text { expense associated with repairs } \\
\text { (including transportation time and fuel } \\
\text { to obtain parts) }\end{array}$ & $\mathrm{X}$ & $\mathrm{X}$ \\
\hline $\begin{array}{l}\text { Loss of arable land due to erosion caused } \\
\text { by wild pigs }\end{array}$ & $\mathrm{X}$ & \\
\hline Damage to access roads & $\mathrm{X}$ & $\mathrm{X}$ \\
\hline Depredation of livestock by wild pigs & & $\mathrm{X}$ \\
\hline $\begin{array}{l}\text { Possible increased depredation by coyotes } \\
\text { on account of wild pig damage to fencing }\end{array}$ & & $\mathrm{X}$ \\
\hline $\begin{array}{l}\text { Injury and death of livestock from running } \\
\text { into fencing after suspected encounters } \\
\text { with wild pigs }\end{array}$ & & $\mathrm{X}$ \\
\hline $\begin{array}{l}\text { Loss of livestock feed and supplements to } \\
\text { wild pigs }\end{array}$ & & $\mathrm{X}$ \\
\hline $\begin{array}{l}\text { Loss of expected livestock weight } \\
\text { conversion because of stress or } \\
\text { consumption/soiling of feed by wild pigs }\end{array}$ & & $\mathrm{X}$ \\
\hline $\begin{array}{l}\text { Vaccinating cattle for brucellosis solely } \\
\text { because of wild pigs }\end{array}$ & & $\mathrm{X}$ \\
\hline $\begin{array}{l}\text { Possible spread/transmission of disease } \\
\text { (anthrax) to livestock by wild pigs }\end{array}$ & & $\mathrm{X}$ \\
\hline $\begin{array}{l}\text { Damage to pastures and costs associated } \\
\text { with spraying pastures to control weeds } \\
\text { in disturbed areas }\end{array}$ & & $\mathrm{X}$ \\
\hline
\end{tabular}

We did not investigate the extent to which the reduction of deer was perceived as a benefit among participants.

\subsection{Multiplication factor}

Two of the twenty-three participant observations were dropped from the multiplication factor analysis due to incomplete data (e.g., failure to provide a stated value). For the remaining 21 participants, the average stated value (i.e., a participant's initial best estimate of total wild pig costs in 2018) was US $\$ 37,471$, and the average calculated value (i.e., the itemized accounting of a participant's costs in 2018 revealed during the interview) was US\$107,443 (Table 3 ). ${ }^{7}$ The resulting average multiplication factor across all producer categories (crop, livestock, and mixed) was 2.9. Thus, based solely on participant interview data, participants initially underestimated their total costs associated with wild pigs by a factor of nearly three. By category, the average multiplication factor was highest for crop producers (4.6), followed by livestock producers (1.9) and mixed producers (1.6). The largest cost category generally omitted in participants' stated values was opportunity cost, comprising $66 \%, 23 \%$, and $15 \%$ of the calculated values for crop producers, livestock producers, and mixed producers, respectively. For crop producers, average opportunity costs alone were three times higher than the average stated value. Other costs commonly omitted in participants' stated values were time/labor costs associated with wild pig management and control, and additional time and fuel required at planting and harvest. For all 21 participants, the total calculated value for 2018 was more than US $\$ 2.3$ million across approximately 76,000 acres in production.

\section{Discussion}

Our study revealed a broad range of direct and indirect impacts and costs associated with wild pigs for the agricultural producers in our sample. Some - like the possible spread of anthrax and the creation of more depredation opportunities for coyotes - were speculative and warrant further investigation. Most, however, were based upon direct evidence and were experienced by multiple participants. Many, like additional costs of time and fuel from reduced tractor speed, reduced yields following replanting, and loss of livestock weight conversion, have not figured into any published wild pig damage estimates as far as we are aware. Other costs, like those associated with wild pig management and control, may have been only partially accounted for in published reports. For example, Anderson et al. (2016) utilized a questionnaire that directed producers to report their costs, including labor, for specified control methods; for fencing, producers were directed to report only installation costs. This may have resulted in significant underreporting of total costs for the control methods and fencing. We found that when we asked participants about their total costs, including time, associated with a management or control method, their initial responses were usually limited to costs associated with purchasing, building, or installing a particular method. Costs associated with operation, maintenance, and repair - which were typically much higher - were usually revealed only after we asked specific follow-up questions designed to elicit this information. Even then, participants were sometimes unable to estimate how much time they spent the previous year on routine maintenance and operation activities associated with wild pigs. This highlights a challenge of producing robust estimates of total costs from surveys and interviews alike.

While previous studies have found that producers' estimates of direct crop damage tend to be fairly accurate when compared to field estimates (Elser et al., 2019; Johnson-Nistler et al., 2005; Conover 2002), we found that when participants were asked to estimate their total costs associated with wild pigs, they initially underestimated their costs, including both direct and indirect costs, by a factor of nearly three, on average. The extent of underestimation was even greater among crop producers, largely because their unreported opportunity costs were typically higher than those of livestock producers. This reflects that participants often failed to consider or recollect opportunity costs, time/labor costs, and other categories of indirect costs unless and until

\footnotetext{
7 If a participant was unable to provide an estimate for a particular cost category (e.g., time/labor spent on operating snares and traps and cost of lost livestock feed), the cost was not included in the calculated value. We did, however, include all costs which participants were able to estimate, including costs not directly related to agriculture production, such as the cost of wild pig vehicle collisions.
} 
Table 3

Average calculated value components and stated values by producer category.

\begin{tabular}{|c|c|c|c|c|c|c|}
\hline Producer category & $\begin{array}{l}\operatorname{Loss}^{\mathrm{a}} \\
\text { (US\$) }\end{array}$ & Management $\operatorname{costs}^{\mathrm{b}}$ (US\$) & Opportunity costs (US\$) & Calculated value (US\$) & $\begin{array}{l}\text { Stated value } \\
\text { (US\$) }\end{array}$ & Multiplication factor \\
\hline Crops & $\begin{array}{l}64,061.58 \\
(27 \%)\end{array}$ & $\begin{array}{l}15,800.08 \\
(7 \%)\end{array}$ & $\begin{array}{l}155,353.56 \\
(66 \%)\end{array}$ & $\begin{array}{l}235,215.22 \\
(100 \%)\end{array}$ & $\begin{array}{l}51,583.33 \\
-\end{array}$ & 4.6 \\
\hline Livestock & $\begin{array}{l}36,725.92 \\
(63 \%)\end{array}$ & $\begin{array}{l}8113.82 \\
(14 \%)\end{array}$ & $\begin{array}{l}13,196.11 \\
(23 \%)\end{array}$ & $\begin{array}{l}58,035.85 \\
(100 \%)\end{array}$ & $\begin{array}{l}31,111.11 \\
-\end{array}$ & 1.9 \\
\hline Mixed & $\begin{array}{l}35,817.44 \\
(66 \%)\end{array}$ & $\begin{array}{l}10,002.08 \\
(19 \%)\end{array}$ & $\begin{array}{l}7946.26 \\
(15 \%)\end{array}$ & $\begin{array}{l}53,765.78 \\
(100 \%)\end{array}$ & $\begin{array}{l}32,900.00 \\
-\end{array}$ & 1.6 \\
\hline $\begin{array}{l}\text { Combined } \\
\text { Categories }\end{array}$ & $\begin{array}{l}44,276.68 \\
(41 \%)\end{array}$ & $\begin{array}{l}10,853.83 \\
(10 \%)\end{array}$ & $\begin{array}{l}52,322.57 \\
(49 \%)\end{array}$ & $\begin{array}{l}107,443.07 \\
(100 \%)\end{array}$ & $\begin{array}{l}37,471.00 \\
-\end{array}$ & 2.9 \\
\hline
\end{tabular}

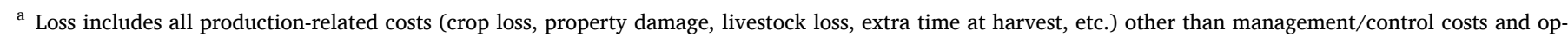
portunity costs.

b Management costs include all costs (time, materials, labor, etc.) associated with controlling or managing wild pigs.

we asked very specific and probing questions that required them to reflect on the categories. As one participant explained in response to a question about time spent monitoring his fencing for wild pig damage, "It's funny you ask something to me like that because it is a regular routine, but it's so routine you don't even realize you're doing it." Importantly, management costs and opportunity costs comprised $59 \%$ of the total costs (the calculated value) for participants. This suggests, among other things, that broadly worded survey questions about categories of wild pig costs (e.g., control costs, costs at planting, livestock damage) likely fail to elicit data about the full range of costs a producer may have experienced.

There are, however, several important caveats concerning the calculated values and resulting multiplication factor. Some of the cost components included in the calculated values were very rough estimations - particularly those involving time/labor and estimates of depredation rates by wild pigs versus coyotes. We also likely overestimated costs associated with purchasing and installing fencing because the decision to install fencing may have been partly motivated by other concerns (e.g., coyote depredation). This cost component of the calculated value was relatively minor, however, because we allocated only a small fraction of the fencing cost to 2018, based upon the participant's estimate of the expected useful life of the fence (typically 10 years or greater). There may also have been bias in the values reported by participants to the extent any of them perceived potential benefit from reporting inflated values (e.g., additional government assistance). We note, however, that nearly all participants refused to provide one or more cost values that we requested because they found it too speculative, somewhat undercutting the notion that they may have intentionally exaggerated other costs. Indeed, we believe the calculated value is likely a significant underestimate of the total wild pig-related costs experienced by participants in 2018 because of the number of times we were unable to obtain cost estimates from producers for confirmed impacts. Cost categories like wear and tear of machinery, loss of livestock feed, and time associated with operating traps and snares were largely excluded from the calculated values and resulting multiplication factor.

With these findings, we call attention to the critical importance of publishing estimates that better represent the full range of costs wild pigs impose on agricultural producers. Damage and cost estimates provide an easily grasped measure of the problem's seriousness, and they can help ensure that adequate attention and resources are directed at mitigating impacts on producers. One participant, who previously allowed scientists to calculate field-based crop damage estimates on his operation, remarked that it would be "devastating" if scientists only published estimates of direct crop losses because it would give decisionmakers a false impression of the magnitude of the problem for producers. In Texas, where efforts to eliminate wild pigs may be met with resistance from a minority of hunters who specialize in wild pig hunting (McLean et al., 2021), a more complete accounting of wild pig impacts on producers could help state lawmakers strike an appropriate balance between supporting the wild pig hunting industry and protecting its agriculture sector. To that end, our findings can inform the design of better surveys capable of producing generalizable estimates of many of the direct and indirect costs we identified. The difficulties we described in obtaining estimates of certain costs also suggest the need for other types of studies. For example, researchers could provide producers an incentive to maintain a daily log of their time spent on wild pig-related tasks. In addition, a first attempt at quantifying additional wear and tear on machinery could compare machinery service records or costs for producers affected by wild pigs to producers in a control group. With resources and creativity, some of the more speculative impacts we identified could be subjected to rigorous inquiry and quantified. In so doing, the wild pig research community can shed light on a growing problem (Snow et al., 2017) that imposes a substantial and likely underappreciated burden on agricultural producers in Texas and beyond.

\section{Disclosure of interest}

The authors report no conflicts of interest.

\section{Data availability}

Participants of this study did not agree for their data to be shared publicly, so supporting data is not available.

\section{Funding}

This research was supported by the U.S. Department of Agriculture, Animal and Plant Health Inspection Service.

\section{Disclaimer}

The findings and conclusions in this publication are those of the authors and should not be construed to represent any official USDA or U. S. Government determination or policy. Mention of commercial products does not represent an endorsement by the U.S. government.

\section{Declaration of competing interest}

The authors declare that they have no known competing financial interests or personal relationships that could have appeared to influence the work reported in this paper.

\section{Acknowledgements}

We are grateful to U.S. Department of Agriculture, Animal and Plant Health Inspection Service for funding this research. We wish to thank the USDA/APHIS Wildlife Services employees in Texas, without whose support and expert guidance this research would not have been possible. We also wish to thank the 23 producers who generously gave their time to participate in this research. Finally, we are grateful to Cheryl Dutro 
for her invaluable help in transcribing interview recordings. The Colorado State University Institutional Review Board reviewed and approved the research protocol for this study (Protocol ID 19-9244H).

\section{References}

Anderson, A., Slootmaker, C., Harper, E.E., Miller, R., Shwiff, S.A., 2019. Predation and disease-related economic impacts of wild pigs on livestock producers in 13 states. Crop Protect. 121, 121-126.

Anderson, A., Slootmaker, C., Harper, E.E., Holderieath, J., Shwiff, S.A., 2016. Economic estimates of feral swine damage and control in 11 US states. Crop Protect. 89, 89-94.

Barrios-Garcia, M.N., Ballari, S.A., 2012. Impact of wild boar (Sus scrofa) in its introduced and native range: a review. Biol. Invasions 14, 2283-2300.

Beasley, J.C., Ditchkoff, S.S., Mayer, J.J., Smith, M.D., Vercauteren, K.C., 2018. Research priorities for managing invasive wild pigs in North America. J. Wildl. Manag. 82 (4), 674-681.

Bevins, S.N., Pedersen, K., Lutman, M.W., Gidlewski, T., Deliberto, T.J., 2014. Consequences associated with the recent range expansion of nonnative feral swine. Bioscience 64 (4), 291-299.

Bolds, S.A., Graeme Lockaby, B., Ditchkoff, S.S., Smith, M.D., VerCauteren, K.C., 2021. Impacts of a large invasive mammal on water quality in riparian ecosystems. J. Environ. Qual. 50, 441-453.

Boyer, K.S., Fairbanks, W.S., Rohla, C., Webb, S.L., 2020. Surficial soil damage by wild pigs (Sus scrofa) decreases pecan harvest efficiency. Crop Protect. 128, 1-4.

Carlisle, K.M., Harper, E.E., Shwiff, S.A., 2020. An examination of ethical attitudes towards wild pig (Sus scrofa) toxicants in the United States. Int. J. Pest Manag. https://doi.org/10.1080/09670874.2020.1791372.

Caplenor, C.A., Poudyal, N.C., Muller, L.I., Yoest, C., 2017. Assessing landowners' attitudes toward wild hogs and support for control options. J. Environ. Manag. 201, $45-51$.

Conover, M., 2002. Resolving Human-Wildlife Conflicts: the Science of Wildlife Damage Management. CRC Press, Boca Raton.

Corn, J.L., Jordan, T.R., 2017. Development of the national feral swine map, 1982-2016. Wildl. Soc. Bull. 41 (4), 758-763.

Elser, J.L., Lindell, C.A., Steensma, K.M.M., Curtis, P.D., Leigh, D.K., Siemer, D.K., Boulanger, J.R., Shwiff, S.A., 2019. Measuring bird damage to three fruit crops: a comparison of grower and field estimates. Crop Protect. 123, 1-4.

Etikan, I., Sulaiman, A.M., Rukayya, S.A., 2016. Comparison of convenience sampling and purposive sampling. Am. J. Theor. Appl. Stat. 5 (1), 1-4.
Floress, K., Sachdeva, S., 2019. Novel and controversial methods in the social sciences: introduction to special issue. Soc. Nat. Resour. 32 (10), 1077-1079.

Froehly, J.L., Beane, N.R., Evans, D.E., Cagle, K.E., Jachowski, D.S., 2020. Using multiscale behavioral investigations to inform wild pig (Sus scrofa) population management. PloS One 15 (2), e0228705.

Gleaton, C., Robinson, J., 2016. Facts about Texas and U.S. Agriculture. Texas A\&M Agrilife Extension Service, College Station, Texas. Available at. https://agecoext. tamu.edu/wp-content/uploads/2016/06/FullReport.pdf [verified April 2021].

Grady, M.J., Harper, E.E., Carlisle, K.M., Ernst, K.H., Shwiff, S.A., 2019. Assessing public support for restrictions on transport of invasive wild pigs (Sus scrofa) in the United States. Journal of Environmental Management 237, 488-494.

Johnson-Nistler, C.M., Knight, J.E., Cash, S.D., 2005. Considerations related to Richardson's ground squirrel control in Montana. Agron. J. 97 (5), 1460-1464.

Keiter, D.A., Mayer, J.J., Beasley, J.C., 2016. What is in a 'common' name? A call for consistent terminology for nonnative Sus scrofa. Wildl. Soc. Bull. 40 (2), 384-387.

Lewis, J.A., Corn, J.L., Mayer, J.J., Jordan, T.R., Farnsworth, M.L., Burdett, C.L., VerCauteren, K.C., Sweeney, S.J., Miller, R.S., 2019. Historical, current, and potential population size estimates of invasive wild pigs (Sus scrofa) in the United States. Biol. Invasions 21, 2373-2384.

McKee, S., Anderson, A., Carlisle, K., Shwiff, S.A., 2020. Economic estimates of invasive wild pig damage to crops in 12 US states. Crop Protect. 132, 105105.

Mengak, M.T., 2016. 2015 Georgia Wild Pig Survey FInal Report. Warnell School of Forestry and Natural Resources Outreach Publication, Athens, Georgia, pp. 16-23.

McLean, H.E., Teel, T.L., Bright, A.D., Jaebker, L.M., Tomecek, J.M., Frank, M.G., Connally, R.L., Shwiff, S.A., Carlisle, K.M., 2021. Understanding tolerance for an invasive species: an investigation of hunter acceptance capacity for wild pigs (Sus scrofa) in Texas. J. Environ. Manag. 285, 112143.

NASS, 2017. Census of Agriculture. Available at. https://www.nass.usda.gov /Publications/AgCensus/2017/Full_Report/Volume_1,_Chapter_1_State_Lev el/Texas/ [verified April 2021].

Pimentel, D., 2007. Environmental and Economic Costs of Vertebrate Species Invasions into the United States. Managing Vertebrate Invasive Species 38. Available at. http://digitalcommons.unl.edu/nwrcinvasive/38 [verified April 2021].

Poudyal, N.C., Caplenor, C., Joshi, O., Maldonado, C., Muller, L.I., Yoest, C., 2017. Characterizing the economic value and impacts of wild pig damage on a rural economy. Hum. Dimens. Wildl. 22, 538-549.

Snow, N.P., Jarzyna, M.A., VerCauteren, K.C., 2017. Interpreting and predicting the spread of invasive wild pigs. J. Appl. Ecol. 54, 2022-2032.

Tongco, D.C., 2007. Purposive sampling as a tool for informant selection. Ethnobot. Res. Appl. 5, 147-158.

Yin, R.K., 2003. Case Study Research, Design, and Methods. Sage, Thousand Oaks. 